\title{
Clinical manifestations of Rathke's cleft cysts and their natural progression during 2 years in children and adolescents
}

\author{
Jo Eun Jung, MD', \\ Juhyun Jin, $M D^{1}$, \\ Mo Kyung Jung, $M D^{1}$, \\ Ahreum Kwon, MD', \\ Hyun Wook Chae, MD', \\ Duk Hee Kim, MD, PhD', \\ Ho-Seong Kim, MD, PhD ${ }^{1}$
}

'Department of Pediatrics, Severance Children's Hospital, Endocrine Research Institute, Yonsei University College of Medicine, Seoul, ${ }^{2}$ Department of Pediatrics, Sowha Children's Hospital, Seoul, Korea
Received: 20 September, 2016

Revised: 14 October, 2016

Accepted: 20 March, 2017

Address for correspondence: Ho-Seong Kim, MD, PhD

Department of Pediatrics, Severance Children's Hospital, Endocrine Research Institute, Yonsei University College of Medicine, 50-1 Yonsei-ro, Seodaemun-gu, Seoul 03722, Korea Tel: +82-2-2228-2069

Fax: +82-2-393-9118

E-mail:kimho@yuhs.ac

https://orcid.org/0000-0003-1135099X
Purpose: Rathke's cleft cyst (RCC) is an asymptomatic benign lesion. With increased interest in pediatric endocrinology, the prevalence of RCCs in children is also increasing. However, the clinical relevance and proper management of RCC is not well defined in children. Therefore, we investigated the clinical manifestations and radiologic features of RCC in children and adolescents, as well as the natural progression of RCC.

Methods: We retrospectively reviewed the medical records of 91 children and adolescents with RCC diagnosed with magnetic resonance imaging (MRI) in Severance Children's Hospital from January 2006 to December 2015. The clinical, hormonal, and imaging findings were analyzed in patient groups classified according to age. The size of each cyst was assessed in sixty patients who underwent follow-up MRI during the 2 years.

Results: Female patients were predominant (64 vs. 27). The common clinical features at presentation were endocrine dysfunction (59.3\%), headache (23.0\%), and dizziness (4.4\%). Symptoms related to endocrine disorders were more frequent in younger patients. In 7 patients managed surgically, the cysts were significantly larger and more frequently located in the suprasellar region. Of 60 nonsurgical patients with a follow-up MRI performed within 2 years after the diagnosis, the RCC size increased in about $26.7 \%(n=16)$.

Conclusion: Although $94.4 \%$ of the patients with RCC had clinical symptoms, surgery was performed in only about $7.5 \%$ of patients. RCC is associated with pituitary insufficiency, thus, baseline and follow-up endocrine function tests are required. Additionally, regular MRI follow-up is required in long-term period to monitor change in size.

Keywords: Central nervous system cysts, Child, Adolescent, Endocrine system diseases, Hormones, Natural history

\section{Introduction}

Rathke's cleft cyst (RCC) is a benign, sellar, and/or suprasellar lesion originating from the remnants of Rathke's pouch, which disappears during the embryonic period ${ }^{1,2}$. RCCs are $^{2}$ usually found incidentally in adults, with an incidence of about $12 \%-33 \%$ in autopsy cases ${ }^{3-6}$. Although most cases of RCC are asymptomatic, some RCCs progress to enlarged cysts, leading to compression of adjacent structures and resulting in clinical symptoms such as headache, visual disturbance, and endocrinopathy. It is also assumed that the change of cyst in the size would be related to an imbalance between the secretion and absorption of cyst contents, and may cause leakage, intracystic hemorrhage, and infection ${ }^{7,8)}$.

Recently, the prevalence of RCC in children is gradually increasing, owing to the increased 
number of work-ups for detecting growth and puberty disorders in children, as well as the improved quality of brain imaging, allowing the identification of RCC. However, most previous studies on RCC were based on adult data, and the number of enrolled patients was limited. In addition, the optimal guideline for the management of asymptomatic RCC is not well defined because of the uncertainty about the natural course of asymptomatic RCC.

In the present study, we aimed to investigate the clinical characteristics of RCC in children and adolescents, and the natural course of asymptomatic RCC in patients undergoing brain magnetic resonance imaging (MRI) at least 2 times during 2 years.

\section{Materials and methods}

\section{Patients}

Ninety-one patients with RCC (age, 1-18 years) who visited Severance Children's Hospital from January 2006 to December 2015 were included. RCC was diagnosed in these patients based on the results of sellar MRI. This study's protocol was approved by the Institutional Review Board of Yonsei University Severance Hospital (approval number: 4-2017-0121). Written informed consent was obtatined from all patients.

\section{Analysis of clinical and radiological data}

We obtained the baseline information of patients, including clinical symptoms, age, sex, height, weight, and body mass index, through a retrospective review of medical records. The patients were categorized according to age at diagnosis into the school-age group (subdivided into elementary and middle or high school) and the preschool-age group. The height standard deviation score (SDS) and weight SDS were adjusted for chronological age (CA) and sex were calculated by using the 2007 growth reference for Korean children and adolescents. Endocrinological evaluation included measurement of the bone age (BA) and the basal level of free thyroxine, thyroidstimulating hormone (TSH), insulin-like growth factor-I, insulin-like growth factor binding protein-3, luteinizing hormone (LH), follicle stimulating hormone (FSH), estradiol, testosterone, adrenocorticotropic hormone (ACTH), cortisol, and prolactin. Some selected cases required more detailed examinations, such as a combined pituitary function test or a gonadotropin releasing hormone $(\mathrm{GnRH})$ stimulation test.

The following criteria were used for the diagnosis of various endocrine disorders. The definition of growth hormone deficiency (GHD) included (1) short stature, below the third percentile for age or $>2$ standard deviations below the mean stature; (2) a peak growth hormone (GH) level of $<10 \mathrm{ng} /$ $\mathrm{mL}$ in 2 types of GH stimulation tests, by using levodopa and insulin; and (3) delayed BA comparing to CA. The criteria for the diagnosis of central precocious puberty (CPP) were (1) onset of pubertal characteristics before the age of 8 years in girls and 9 years in boys; (2) a peak LH level of $>5 \mathrm{mIU} / \mathrm{mL}$ in the GnRH stimulation test; and (3) advanced BA comparing to CA. TSH deficiency was defined as the absence of a TSH increase during the thyrotropin releasing hormone stimulation test. ACTH deficiency was diagnosed when no increase in cortisol was elicited during the insulin tolerance test (peak cortisol level, $<20 \mu \mathrm{g} / \mathrm{dL}$ ). Lastly, hyperprolactinemia was defined as a baseline prolactin level of $>25 \mathrm{ng} / \mathrm{mL}$.

Diabetes insipidus (DI) was defined to the disease with polyuria and polydipsia which is originated from the deficiency of antidiuretic hormone.

The MRI findings of RCCs, confirmed by neurology radiologists, were classified based on different characteristics, such as the size (height and width), location, and signal intensities of T1- and T2-weighted images (high, equal, and low).

\section{Statistical analysis}

All statistical analyses were conducted with IBM SPSS Statistics ver. 20.0 (IBM Co., Armonk, NY, USA). Continuous variables such as age, height, and weight are presented as the mean \pm standard. Categorical variables such as sex, clinical symptoms at diagnosis and MRI findings were expressed by using frequencies and percentages and were compared with

Table 1. Demographic and clinical characteristics of the 91 patients included in the analysis

\begin{tabular}{lc}
\hline Characteristic & Value \\
\hline Age (yr), mean \pm SD (range) & $9.7 \pm 4.2(1.2-18.0)$ \\
Sex & $27(29.7)$ \\
Male & $64(70.3)$ \\
Female & $0.37 \pm 1.51$ \\
Height SDS & $0.30 \pm 1.27$ \\
Weight SDS & $0.11 \pm 1.12$ \\
Body mass index SDS & $54(59.3)$ \\
Endocrinologic abnormality, $\mathrm{n}(\%)$ & 34 \\
Early puberty & 13 \\
Short stature & 4 \\
Polyuria & 2 \\
Galactorrhea & 1 \\
Menstrual problem & $32(35.1)$ \\
Neurologic abnormality, $\mathrm{n}(\%)$ & 21 \\
Headache & 4 \\
Dizziness & 3 \\
Visual disturbance & 2 \\
Syncope & 1 \\
Seizure & 1 \\
Tinnitus & 54 \\
Asymptomatic, $\mathrm{n}$ (\%) & \\
Treatment & \\
Conservative management & \\
Surgical management & \\
\hline SDS, standard deviation score & \\
\hline
\end{tabular}

SDS, standard deviation score. 
other variables by using chi-square test. A $P$-value of $<0.05$ was considered significant.

\section{Results}

\section{Baseline clinical characteristics of RCC}

The demographic and clinical characteristics of 91 patients are shown in Table 1. Of total patients, 27 were boys (29.7\%) and 64 were girls $(70.3 \%)$. The mean age of the patients was 9.7 years (range, $1.2-18.0$ years). More than half of the patients had symptoms related to the endocrine system $(n=54,59.3 \%)$, such as early puberty, short stature, polyuria, galactorrhea, and menstrual disturbance. Thirty-two patients (35.1\%) had symptoms related to the neurologic system, such as headache $(\mathrm{n}=21,23.1 \%)$, dizziness $(\mathrm{n}=4,4.4 \%)$, and visual disturbance $(\mathrm{n}=3,3.3 \%)$. In addition, asymptomatic patient was $5(5.6 \%)$ (Table 1).

Fifty-one patients performed endocrinologic function test and Table 2 summarized the results. The most common endocrine dysfunction was CPP $(\mathrm{n}=36,70.6 \%, 33$ isolated, 3 combined endocrinopathy), followed by GHD ( $\mathrm{n}=14,27.5 \%$, 5 isolated, 9 combined endocrinopathy), DI ( $\mathrm{n}=3,5.9 \%, 1$ isolated,

\section{Table 2. Results of endocrine evaluation in $\mathbf{5 1}$ patients}

\begin{tabular}{lccc}
\hline Variable & Total & Isolated & Combined \\
\hline Central precocious puberty & 36 & 33 & 3 \\
Growth hormone deficiency & 14 & 5 & 9 \\
TSH deficiency & 5 & 0 & 5 \\
Diabetes insipidus & 3 & 1 & 2 \\
Hyperprolactinemia & 2 & 1 & 1 \\
ACTH deficiency & 1 & 0 & 1 \\
Gonadotropin deficiency & 1 & 0 & 1 \\
Normal & 1 & - & - \\
\hline RCC, Rathke's cleft cyst; TSH, thyroid stimulating hormone; ACTH, \\
adenocorticotropic hormone.
\end{tabular}

2 combined endocrinopathy), hyperprolactinemia ( $\mathrm{n}=2,3.9 \%$, 1 isolated, 1 combined endocrinopathy), ACTH deficiency $(\mathrm{n}=1,2.0 \%, 1$ combined endocrinopathy) and gonadotropin deficiency $(\mathrm{n}=1,2.0 \%, 1$ combined endocrinopathy. Only 1 patient $(2.0 \%)$ of them had normal results.

Ten of 91 patients (11.0\%) were multiple endocrine dysfunction; three patients of GHD with CPP, 2 patients of GHD with DI, 2 patients of GHD with TSH deficiency, 1 patient of GHD, TSH deficiency with ACTH deficiency, 1 patient of TSH deficiency accompanying hyperprolactinmeia and 1 patient of GHD, TSH deficiency, and accompanying gonadotropin deficiency.

\section{Clinical manifestations in the groups classified according to age}

The presenting symptoms according to age group were analyzed (Table 3 ). In the preschool-age group ( $<7$ years), early puberty $(n=12,46.2 \%)$, short stature $(n=5,19.2 \%)$, and headache $(\mathrm{n}=7,27.0 \%)$ were common symptoms. Elementary-school children ( $7-12$ years) also had symptoms of early puberty $(\mathrm{n}=22$, $48.8 \%)$ and short stature $(\mathrm{n}=5,11.0 \%)$, but presented with a greater variety of neurological symptoms than the other groups. Lastly, the middle school or high school group (>12 years) mainly experienced neurological symptoms, such as headache $(n=9,45.0 \%)$. Clinical symptoms related to endocrine system, especially related to growth and puberty appeared significantly more frequent in before-middle school patients than in middle or high school aged patients $(P<0.01)$.

\section{Clinical characteristics of the patients who underwent surgery}

Seven patients underwent surgical treatment, either in an attempt to resolve pressure symptoms such as headache and visual field defect or to investigate the possibility of malignancy (Table 4). In all 7 patients who underwent surgery, the selected

Table 3. The incidence of chief complaints in patients with RCC, stratified to age group

\begin{tabular}{|c|c|c|c|c|}
\hline Variable & Preschool $(<7 \mathrm{yr}, \mathrm{n}=26)$ & Elemantary school $(7-12 \mathrm{yr}, \mathrm{n}=45)$ & Middle or high school (>12 yr, $\mathrm{n}=20)$ & $P$-value \\
\hline Endocrine $(n=54,59.3 \%)$ & & & & $<0.01$ \\
\hline Short stature & $5(19.2)$ & $5(11.0)$ & $3(15.0)$ & \\
\hline Early puberty & $12(46.2)$ & $22(48.8)$ & $0(0)$ & \\
\hline Dysmenorrhea & $0(0)$ & $0(0)$ & $1(5.0)$ & \\
\hline Polyuria & $0(0)$ & $3(6.7)$ & $1(5.0)$ & \\
\hline Galactorrhea & $0(0)$ & $0(0)$ & $2(10.0)$ & \\
\hline Neurologic $(n=32,35.1 \%)$ & & & & 0.130 \\
\hline Headache & $7(27.0)$ & $5(11.0)$ & $9(45.0)$ & \\
\hline Dizziness & $0(0)$ & $3(6.7)$ & $1(5.0)$ & \\
\hline Syncope & $0(0)$ & $1(2.2)$ & $1(5.0)$ & \\
\hline Seizure & $1(3.8)$ & $0(0)$ & $0(0)$ & \\
\hline Tinnitus & $0(0)$ & $1(2.2)$ & $0(0)$ & \\
\hline Visual disturbance & $0(0)$ & $2(4.5)$ & $1(5.0)$ & \\
\hline Asymptomatic $(n=5,5.5 \%)$ & $1(3.8)$ & $3(6.7)$ & $1(5.0)$ & 0.33 \\
\hline
\end{tabular}

Values are presented as number (\%).

RCC, Rathke's cleft cyst. 
operation method was transsphenoidal aspiration and the RCC was confirmed pathologically. After the operation, clinical symptoms related to pressure were improved after surgery in all 7 patients. On the other hand, the endocrine functions were aggravated in 2 of 7 patients, improved in 1 patient, and remained the same in 4 patients after surgery (Table 4). None of the 7 patients experienced recurrence of RCC.

We also analyzed the characteristics of RCC comparing 2 groups, surgical treatment group and nonsurgical treatment group. The RCC size of patients who required surgery was significantly larger than that of patients who did not underwent surgery (Table 5). Moreover, the RCC was more frequently located in suprasellar in patients who required surgical treatment. However, there were no differences signal intensities between surgical and nonsurgical group.

\section{Natural progression of RCC size on image study of during 2 years}

Sixty patients among total 31 patients underwent followup MRIs during 2 years. Follow-up MRIs showed that the size of RCCs increased in 16 of 60 patients $(26.7 \%)$, remained the same in 21 patients $(48.3 \%)$, and decreased in 15 of 60 patients $(25.0 \%)$. None of the patients with increased size of RCCs needed the surgical treatment in follow-up period.

\section{Discussion}

We evaluated the clinical characteristics of 91 children and adolescents with RCCs diagnosed with sellar MRI, and analyzed the presenting symptoms in the groups classified according to age. Our study demonstrated a female preponderance in RCC, as in previous studies of adults ${ }^{9,10)}$. Presenting symptoms related to CPP, which is more common in girls than in boys, and menstrual disorders which are also presented only in girls may lead to frequent detection of RCC in female. On the other hand, the most 2 common chief complaints of boys were short stature (37.0\%) and headache $(25.9 \%)$, differently from those of girls early puberty (48.4\%) and headache (23.4\%).
In this study, symptomatic RCC was noted in most of the patients (86 of 91 patients, $94.4 \%$ ), whereas asymptomatic RCC was observed in only $5.6 \%$ (5 of 91 patients). The frequency of each symptom in symptomatic RCC patients has been reported to be variable owing to the diversity of the enrolled patient cohorts $^{8,9,11-13)}$. Previous studies of adults' data reported that frequent clinical symptoms of RCC include headache, visual disturbance, and pituitary dysfunction. The prevalence of each clinical symptom showed wide ranges according to studies. Headache appeared in $44 \%-81 \%$ of patients, visual disturbance in $11 \%-67 \%$, and pituitary dysfunction in $30 \%-60 \%$ of symptomatic cases ${ }^{9,10)}$. In the present study, headache $(n=21$, $23.1 \%)$ and visual disturbance $(n=3,3.3 \%)$ were less frequently observed, and pituitary dysfunction $(\mathrm{n}=54,59.3 \%)$ showed a similar incidence to that reported in previous studies. Especially, pituitary dysfunction related to growth or puberty, such as short stature and early puberty appeared to only children or adolescents of our study differed from previous studies. Furthermore, analysis of the presenting neurologic symptoms in the groups classified according to the age showed that headache

Table 5. Comparison of magnetic resonance imaging findings between the surgical and medical management groups

\begin{tabular}{lccc}
\hline Variable & $\begin{array}{c}\text { Medical } \\
(\mathrm{n}=84)\end{array}$ & $\begin{array}{c}\text { Surgical } \\
(\mathrm{n}=7)\end{array}$ & P-value \\
\hline Size, height $(\mathrm{mm})$ & $6.4 \pm 3.5$ & $14.0 \pm 7.2$ & 0.05 \\
Size, width $(\mathrm{mm})$ & $10.1 \pm 3.7$ & $15.0 \pm 4.1$ & $<0.01$ \\
Location & & & $<0.01$ \\
$\quad$ Suprasella & $8(9.5)$ & $3(42.8)$ & \\
Pars intermedia + supra extension & $3(3.6)$ & $2(28.6)$ & \\
$\quad$ Pars intermedia & $73(86.9)$ & $2(28.6)$ & \\
T1 intensity & & & 0.07 \\
Hypointense & $23(27.4)$ & $0(0)$ & \\
Isointense & $13(15.5)$ & $4(57.1)$ & \\
$\quad$ Hyperintense & $48(57.1)$ & $3(42.9)$ & \\
T2 intensity & & & 0.16 \\
Hypointense & $68(81.0)$ & $4(57.1)$ & \\
Isointense & $8(4.5)$ & $2(28.6)$ & \\
Hyperintense & $8(4.5)$ & $1(14.3)$ & \\
\hline Values are presented asmeantstandard & &
\end{tabular}

Values are presented as mean \pm standard deviation or number (\%).

Table 4. Characteristics of seven patients who underwent surgery

\begin{tabular}{|c|c|c|c|c|c|c|c|}
\hline Patient No. & Age $(y r) / s e x$ & Reason for surgery & Outcome & $\begin{array}{c}\text { Cyst size } \\
\text { (height } \times \text { width, } \mathrm{mm} \text { ) }\end{array}$ & $\begin{array}{l}\text { Preop endocrine } \\
\text { disorder }\end{array}$ & $\begin{array}{l}\text { Postop endocrine } \\
\text { disorder }\end{array}$ & Recurrence \\
\hline 1 & $9 / F$ & Headache & Improved & $14.2 \times 19.1$ & GHD & Multiple $^{*}$ & No \\
\hline 2 & $15 / \mathrm{M}$ & Headache & Improved & $13.3 \times 9.4$ & GHD & Multiple $^{\dagger}$ & No \\
\hline 3 & $10 / M$ & Visual field defect & Improved & $28 \times 18.1$ & Multiple & Multiple ${ }^{\ddagger}$ & No \\
\hline 4 & $10 / F$ & Suspected malignancy & None & $11.7 \times 17.1$ & Normal & Normal & No \\
\hline 5 & $15 / F$ & $\begin{array}{l}\text { Suspected malignancy, } \\
\text { headache }\end{array}$ & Improved & $8.2 \times 11.1$ & GHD & Normal & No \\
\hline 6 & 18/M & $\begin{array}{l}\text { Suspected malignancy, } \\
\text { headache }\end{array}$ & Improved & $8.6 \times 15.7$ & Multiple $^{\dagger}$ & Multiple $^{\dagger}$ & No \\
\hline 7 & $12 / F$ & Visual field defect & Improved & $18.2 \times 20.1$ & Multiple $^{\ddagger}$ & Multiple ${ }^{\ddagger}$ & No \\
\hline
\end{tabular}

Preop, preoperative; postop, postoperative; GHD, growth hormone deficiency.

"GHD, thyroid stimulating hormone deficiency, and gonadotropin deficiency. ${ }^{\dagger} \mathrm{GHD}$, adrenocorticotropic hormone deficiency, and thyroid stimulating hormone deficiency. ${ }^{\ddagger} \mathrm{GHD}$ and diabetes insipidus. 
and visual disturbance were more common in older children and adolescents, however it does not have significant difference.

Further hormonal study revealed that most of the patients (98.0\%) had pituitary dysfunction, which manifested as CPP, GH deficiency, multiple pituitary hormone deficiency, hyperprolactinemia, and DI. According to the previous several studies of adults, prevalence of pituitary dysfunction in adults ranged from $30.0 \%-100.0 \%{ }^{14)}$.

In previous studies, the indications for the surgical treatment of patients with RCC were controversial. Although the conventional therapy for symptomatic RCCs is surgical resection, not all cases of symptomatic RCCs require surgery for resection-only RCCs with pressure symptoms require surgery. Conservative care with follow-up MRI is recommended in cases of silent RCCs or smaller cysts with mild symptoms, and surgery is preferable for larger cysts with definite pressure symptoms ${ }^{15}$. In our study, 7 patients were operated by transsphenoidal microscopic surgery either to alleviate pressure symptoms or to investigate the possibility of malignancy because of the increasing size of the RCC. RCC was confirmed pathologically in each of these cases. All 7 patients experienced improvement of clinical symptoms after surgery; however, their endocrine dysfunctions did not improve, or was even aggravated in 2 patients. This is one of the reasons for the controversy about the operative treatment of RCC. Because radical resection may lead to a lower recurrence and a higher risk of additional endocrine disorders, transsphenoidal microscopic surgery is the first choice for surgical treatment ${ }^{12,16,17)}$. In addition, follow-up endocrine surveillance is needed after surgical interventions. The several MRI features differed significantly between patients who underwent surgery and those who did not. RCCs were significantly larger and were more frequently located in the suprasellar region in patients who underwent surgery. Otherwise, we could not find any difference of intensity in the T1- or T2-weighted MRI images between patients who underwent surgery and those who did not. RCCs usually appear as homogenous intensity in the region of the pars intermedia ${ }^{7)}$. The homogeneous signal observed in MRI can vary depending on the concentration and composition of the cyst contents, particularly protein, cholesterol, and hemorrhage ${ }^{18-20)}$. Cysts with high protein contents display high intensity in T1-weighted images, and cysts with low water content show low intensity in T2-weighted images ${ }^{21,22)}$. Lesions with high or low intensity in T1-weighted images and low intensity in T2-weighted images were most common in our study and consistent with findings reported in the literature ${ }^{22,23)}$.

Lastly, follow-up MRI was performed in sixty of the 91 patients during 2 years, which showed that the size of RCC increased in 16 of 60 patients $(26.7 \%)$, remained the same in 29 of 60 patients $(48.3 \%)$, and decreased in 15 of 60 patients (25.0\%). Our study demonstrated that most cases of RCCs without pressure symptoms remain the same or decrease in size over time. Further studies about the effect of medical treatment on RCC are required.

Considering limitations of our study, according to age and symptoms related to RCCs which the patients already had, selection bias could develop.

In conclusion, it is necessary to perform both baseline and routine follow-up endocrine testing to detect endocrine dysfunction, because many patients with RCC may have symptoms related to pituitary dysfunction. Surgical resection is required only in RCC cases with pressure symptoms and conservative management of patients with RCC is recommended, in the absence of pressure symptoms. In addition, followup MRI is required, because the size of RCC can change after few years.

\section{Conflict of interest}

No potential conflict of interest relevant to this article was reported.

\section{References}

1. Raper DM, Besser M. Clinical features, management and recurrence of symptomatic Rathke's cleft cyst. J Clin Neurosci 2009; 16:385-9.

2. Voelker JL, Campbell RL, Muller J. Clinical, radiographic, and pathological features of symptomatic Rathke's cleft cysts. J Neurosurg 1991;74:535-44.

3. Esiri M. Russell and Rubinstein's pathology of tumors of the nervous system. Sixth edition. J Neurol Neurosurg Psychiatry 2000;68:538D.

4. Raghunath A, Sampath S, Devi BI, Chandramouli BA, Lal GJ, Chickabasaviah YT, et al. Is there a need to diagnose Rathke's cleft cyst preoperatively? Neurol India 2010;58:6973.

5. Teramoto A, Hirakawa K, Sanno N, Osamura Y. Incidental pituitary lesions in 1,000 unselected autopsy specimens. Radiology 1994;193:161-4.

6. Mukherjee JJ, Islam N, Kaltsas G, Lowe DG, Charlesworth M, Afshar F, et al. Clinical, radiological and pathological features of patients with Rathke's cleft cysts: tumors that may recur. J Clin Endocrinol Metab 1997;82:2357-62.

7. Takanashi J, Tada H, Barkovich AJ, Saeki N, Kohno Y. Pituitary cysts in childhood evaluated by MR imaging. AJNR Am J Neuroradiol 2005;26:2144-7.

8. Oh YJ, Park HK, Yang S, Song JH, Hwang IT. Clinical and radiological findings of incidental Rathke's cleft cysts in children and adolescents. Ann Pediatr Endocrinol Metab 2014;19:20-6.

9. Trifanescu R, Ansorge O, Wass JA, Grossman AB, Karavitaki N. Rathke's cleft cysts. Clin Endocrinol (Oxf) 2012;76:15160.

10. Han SJ, Rolston JD, Jahangiri A, Aghi MK. Rathke's cleft cysts: review of natural history and surgical outcomes. J Neurooncol 2014;117:197-203.

11. Lim HH, Yang SW. Risk factor for pituitary dysfunction in children and adolescents with Rathke's cleft cysts. Korean J 
Pediatr 2010;53:759-65.

12. Potts MB, Jahangiri A, Lamborn KR, Blevins LS, Kunwar S, Aghi MK. Suprasellar Rathke cleft cysts: clinical presentation and treatment outcomes. Neurosurgery 2011;69:105868.

13. Culver SA, Grober Y, Ornan DA, Patrie JT, Oldfield EH, Jane JA Jr, et al. A case for conservative management: characterizing the natural history of radiographically diagnosed Rathke cleft cysts. J Clin Endocrinol Metab 2015;100:39438.

14. Kanter AS, Sansur CA, Jane JA Jr, Laws ER Jr. Rathke's cleft cysts. Front Horm Res 2006;34:127-57.

15. Aho CJ, Liu C, Zelman V, Couldwell WT, Weiss MH. Surgical outcomes in 118 patients with Rathke cleft cysts. J Neurosurg 2005;102:189-93.

16. Brassier G, Morandi X, Tayiar E, Riffaud L, Chabert E, Heresbach N, et al. Rathke's cleft cysts: surgical-MRI correlation in 16 symptomatic cases. J Neuroradiol 1999;26:16271.

17. Binning MJ, Liu JK, Gannon J, Osborn AG, Couldwell WT. Hemorrhagic and nonhemorrhagic Rathke cleft cysts mimicking pituitary apoplexy. J Neurosurg 2008;108:3-8.

18. Saeki N, Sunami K, Sugaya Y, Yamaura A. MRI findings and clinical manifestations in Rathke's cleft cyst. Acta Neurochir (Wien) 1999;141:1055-61.

19. Kucharczyk W, Peck WW, Kelly WM, Norman D, Newton TH. Rathke cleft cysts: CT, MR imaging, and pathologic features. Radiology 1987;165:491-5.

20. Nemoto Y, Inoue Y, Fukuda T, Shakudo M, Katsuyama J, Hakuba A, et al. MR appearance of Rathke's cleft cysts. Neuroradiology 1988;30:155-9.

21. Nishioka H, Haraoka J, Izawa H, Ikeda Y. Magnetic resonance imaging, clinical manifestations, and management of Rathke's cleft cyst. Clin Endocrinol (Oxf) 2006;64:184-8.

22. Bonneville F, Cattin F, Marsot-Dupuch K, Dormont D, Bonneville JF, Chiras J. T1 signal hyperintensity in the sellar region: spectrum of findings. Radiographics 2006;26:93113 .

23. Bonneville F, Chiras J, Cattin F, Bonneville JF. T2 hypointense signal of rathke cleft cyst. AJNR Am J Neuroradiol 2007;28:397. 